\title{
MENINGKATKAN KEMAMPUAN DETEKSI DINI DAN PENATALAKSANAAN GANGGUAN PENDENGARAN DI KALIBARU KULON BANYUWANGI
}

\author{
ENHANCING EARLY DETECTION AND MANAGEMENT \\ OF HEARING LOSS IN KALIBARU KULON BANYUWANGI
}

\author{
Puguh Setyo Nugroho ${ }^{1}$, Nyilo Purnami ${ }^{2}$, Rosa Falerina ${ }^{1}$, Rizka Fathoni Perdana ${ }^{2}$, \\ Alfian Nurfaizi ${ }^{3}$ \\ ${ }^{1}$ Departemen / SMF Ilmu Kesehatan Telinga Hidung Tenggorok Bedah Kepala dan \\ Leher Fakultas Kedokteran Universitas Airlangga, RSUD Dr. Soetomo Surabaya \\ ${ }^{2}$ Departemen / Kelompok Staf Medis Telinga Hidung Tenggorok Bedah Kepala dan \\ Leher Fakultas Kedokteran, Rumah Sakit Universitas Airlangga \\ ${ }^{3}$ Fakultas Kedokteran Universitas Airlangga \\ e-mail: puguh-s-n@fk.unair.ac.id
}

\begin{abstract}
Hearing loss can disrupt communication, which has an impact on social, school, and work environments. Early detection and management of hearing loss can prevent it. The community is hoped to be contributed by raising awareness of hearing loss and its prevention. Therefore, educational activities in the form of counseling and training were carried out for various groups in Kalibaru Kulon village, Kalibaru Sub District, Banyuwangi District, East Java. The aim of the counseling and training on early detection of hearing loss for medical personnel is to increase their knowledge and skills at the Public Health Center (Puskesmas) to perform early detection and management of hearing loss. The purpose of hearing health counseling activities for "Satya Kencana" youth organizations is to increase their knowledge as a strategic age in the community to engage in early detection of hearing loss activities in the community. The training of medical personnel was conducted through lectures, practice skills, and questions and answers (Q\&A), the average pre-test result was $47,67( \pm 15,69)$ and the average post-test was $80,67( \pm 22,73)$. The comparison of both results had significantly different results $(\mathrm{p}<0,0001)$. Hearing health counseling for "Satya Kencana" youth organizations was conducted with lectures and Q\&A. The average pre-test result was 53,08 $( \pm 13,72)$ and the average post-test result was $86,28( \pm 20,81)$. The comparison of both results also showed significantly different results $(\mathrm{p}<0,0001)$.
\end{abstract}

Keywords : early detection, management of hearing loss

\begin{abstract}
Abstrak
Gangguan pendengaran dapat mengganggu komunikasi yang berdampak pada lingkungan sosial, sekolah, dan pekerjaan. Gangguan pendengaran dapat dicegah dengan deteksi dan penatalaksanaan dini gangguan pendengaran. Diharapkan masyarakat dapat berkontribusi dengan meningkatkan kesadaran terhadap gangguan pendengaran dan pencegahannya. Sehingga dilaksanakan kegiatan edukasi berupa penyuluhan dan pelatihan untuk berbagai kalangan di desa Kalibaru Kulon Kecamatan Kalibaru Kabupaten Banyuwangi Jawa Timur. Tujuan kegiatan penyuluhan dan pelatihan deteksi dini gangguan pendengaran untuk tenaga medis adalah meningkatkan pengetahuan dan keterampilan tenaga medis di puskesmas untuk melakukan deteksi dan penatalaksanaan dini gangguan pendengaran. Tujuan kegiatan penyuluhan kesehatan pendengaran untuk karang taruna Satya Kencana adalah meningkatkan pengetahuan karang
\end{abstract}


taruna sebagai usia strategis di masyarakat untuk berperan serta dalam kegiatan deteksi dini gangguan pendengaran di masyarakat. Pelatihan tenaga medis dilakukan dengan metode ceramah, praktek ketrampilan, dan tanya jawab dengan hasil rata-rata pre test $47,67( \pm 15,69)$ dan rata-rata post test $80,67( \pm 22,73)$. Perbandingan hasil pre test dan post test didapatkan hasil yang berbeda signifikan $(\mathrm{p}<0,0001)$. Penyuluhan kesehatan pendengaran untuk karang taruna Satya Kencana dilaksanakan dengan ceramah dan tanya jawab dengan hasil rata-rata pre test $53,08( \pm 13,72)$ dan rata-rata post test $86,28( \pm 20,81)$. Perbandingan hasil pre test dan post test didapatkan hasil yang berbeda signifikan $(\mathrm{p}<0,0001)$.

Kata kunci: deteksi dini, penatalaksanaan gangguan pendengaran

\section{PENDAHULUAN}

Telinga adalah salah satu organ penting pada manusia. Telinga manusia terdiri dari 3 bagian yaitu : (1) telinga luar meliputi daun telinga, liang telinga, dan gendang telinga, (2) telinga tengah meliputi tulang pendengaran dan kavum timpani, (3) dan telinga dalam terdiri dari vestibuler, rumah siput, dan saraf pendengaran. Gelombang suara masuk dari luar ditangkap dan diarahkan oleh daun telinga menuju liang telinga, menggetarkan gendang telinga dan tulang pendengaran, setelah itu masuk ke rumah siput menuju saraf pendengaran dan batang otak untuk dipahami (Nugroho PS, Wiyadi HMS, 2009). Kesehatan telinga perlu dijaga agar pendengaran tetap prima sehingga dapat digunakan sebagai indera pendengaran dan sarana untuk berkomunikasi dan bersosialisasi (Probst, R., 2012: 152).

Kejadian gangguan pendengaran makin meningkat di seluruh dunia. World Health Organization memperkirakan pada tahun 2018 terdapat 466 juta orang di dunia dengan gangguan pendengaran sebanyak $6,1 \%$ dari populasi dunia. Perlu diambil tindakan upaya pencegahan agar kejadian tersebut tidak semakin meningkat di masa yang akan datang. Proyeksi menunjukkan bahwa peningkatan jumlah bisa mencapai 630 juta orang pada tahun 2030 dan mungkin lebih dari 900 juta orang pada tahun 2050. Gangguan pendengaran dapat mengganggu komunikasi yang berdampak pada lingkungan sosial, sekolah, dan pekerjaan. Sehingga diperlukan deteksi dan penatalaksanaan dini gangguan pendengaran yang bertujuan untuk meningkatkan kualitas hidup penderita. Gangguan pendengaran dapat dicegah dengan melakukan sosialisasi gangguan pendengaran lebih awal, segera melakukan penanganan secara dini, dan bekerja untuk memastikan akses layanan dalam rehabilitasi, yaitu penggunaan alat bantu dengar dan komunikasi (Kementerian Kesehatan Republik Indonesia, 2016).

Puskesmas Kalibaru Kulon berada di Kecamatan Kalibaru Kabupaten Banyuwangi Jawa Timur. Luas wilayah Kalibaru Kulon adalah 406,76 $\mathrm{km}^{2}$. Dengan kontur $40 \%$ merupakan dataran rendah dan $60 \%$ merupakan dataran tinggi. Jumlah penduduk adalah 63.381 jiwa dengan laki laki sejumlah 31.530 jiwa dan perempuan sejumlah 32.451 jiwa. Komposisi penduduk berdasarkan usia sebagai berikut : usia 0-5 tahun sejumlah 6.362 jiwa dengan angka kelahiran bayi pada tahun 2019 sebesar 854 jiwa. Anak usia sekolah dan remaja berusia 7-18 tahun sejumlah 14.207 jiwa, penduduk berusia produktif usia 18-59 tahun sejumlah 37.310 jiwa, dan penduduk lansia berusia di atas 65 tahun sejumlah 5.959 jiwa (Puskemas Kalibaru Kulon, 2019).

Data sepuluh penyakit terbanyak pada tahun 2019 di Puskesmas Kalibaru Kulon Banyuwangi didapatkan infeksi akut saluran pernafasan atas, yang merupakan organ Telinga Hidung Tenggorok yaitu sebanyak 994 kali kunjungan penderita dan menduduki posisi kedua setelah penderita penyakit darah tinggi primer. Data puskesmas tahun 2019 
juga menunjukkan bahwa terdapat 108 kasus yang harus dirujukan ke layanan kesehatan yang lebih tinggi yaitu rumah sakit rujukan (Puskemas Kalibaru Kulon, 2019).

Berdasarkan data Puskemas Kalibaru Kulon (2019) dalam aspek program kesehatan indera pendengaran didapatkan beberapa faktor risiko yang dapat diprediksikan. Berdasarkan usia yaitu bayi baru lahir pada tahun 2019 sebesar 854 jiwa. Insiden ketulian kongenital sebesar $0,1 \%$, maka ada sekitar 1 bayi yang kemungkinan memiliki gangguan pendengaran kongenital. Sehingga deteksi dan intervensi dini dilakukan untuk mencegah dampak buruk terhadap kehidupan anak tersebut di masa yang akan datang (White, K.R., 2009:437).

Usia anak usia sekolah dan remaja berusia 7-18 tahun sebanyak 14.207 jiwa (Puskemas Kalibaru Kulon, 2019). Potensi gangguan pendengaran pada anak usia ini cukup besar akan tetapi tidak terdeteksi secara dini. Gangguan pendengaran yang sering terjadi adalah impacted cerumen dengan insiden sebesar 27,41\% (Krug, E., Cieza, A., Chadha, S., et al., 2016:7). Seiring dengan perkembangan teknologi informasi revolusi industri 4.0 dan wabah pandemi COVID 19 yang menyebabkan kegiatan pembelajaran dilakukan secara jarak jauh dalam jaringan (online), ada sebuah ancaman kerusakan indera pendengaran yang disebabkan oleh pemakaian ear phone atau head set yang berlebihan. Gangguan pendengaran karena paparan bising karena pemakaian ear phone atau head set disebut sebagai Noice Induce Hearing Loss (NIHL). Insiden kasus NIHL sebesar 31,55\% dari populasi terjadi pada usia remaja yaitu 14-18 tahun. Hal ini harus mendapatkan pencegahan, deteksi dini dan intervensi secara dini berupa penyuluhan dan penyadaran kepada komunitas remaja (Fligor, B., Chasin, M., Neitzel, R., 2009:595).

Gangguan pendengaran pada usia lanjut yaitu presbikusis dengan insiden sebesar 2,6\% dari populasi sehingga diperkirakan 5.959 jiwa lansia di Kalibaru terdapat 154 jiwa yang mengalami gangguan pendengaran karena faktor usia (Puskemas Kalibaru Kulon, 2019). Gangguan pendengaran pada usia ini cukup memberikan dampak sosial sehingga perlu dilakukan deteksi dan intervensi dini (Weinstein, B.E., 2009: 631).

Tujuan kegiatan pengabdian masyarakat berupa edukasi deteksi dini dan penatalaksanaan gangguan pendengaran yaitu : meningkatkan kualitas kinerja tenaga medis dalam aspek pengetahuan dan ketrampilan deteksi dini serta penatalaksanaan dini gangguan pendengaran untuk membantu mewujudkan program pemerintah khususnya di area kerja puskesmas Kalibaru Kulon Kabupaten Banyuwangi, dan meningkatkan peran serta generasi muda yaitu karang taruna "Satya Kencana" dalam pendampingan keluarga dan lingkungan masyarakat dalam meningkatkan derajat kesehatan pendengaran (Kementerian Kesehatan Republik Indonesia, 2016).

\section{METODE PENGABDIAN MASYARAKAT}

Metode kegiatan program pengabdian masyarakat adalah: pelatihan tenaga medis untuk meningkatkan keterampilan deteksi dini gangguan pendengaran, serta penyuluhan kesehatan pendengaran pada karang taruna.

\section{Pelatihan tenaga medis untuk meningkatkan ketrampilan deteksi dini gangguan pendengaran}

Peserta pelatihan ini adalah tenaga medis yaitu dokter, bidan, dan perawat di lingkungan area kerja Puskemas Kalibaru Kulon Banyuwangi Jawa Timur. Materi pelatihan deteksi 
dini gangguan pendengaran meliputi keterampilan anamnesis, keterampilan pemeriksaan fisik, keterampilan membersihkan telinga, keterampilan pemeriksaan tes bisik, keterampilan pemeriksaan garpu tala, dan pengenalan pemeriksaan penunjang gangguan pendengaran meliputi, antara lain pemeriksaan audiometri, pengenalan pemeriksaan Oto Acoustic Emmision (OAE), dan pemeriksaan Brain Evoked Response Audiometry (BERA) (Browning, G.G., Wormald, P.J., 2018: 919).

Kegiatan dilaksanakan dengan metode ceramah, praktek keterampilan deteksi dini dan diskusi (tanya jawab). Manfaat yang diharapkan dengan pelatihan ini peserta mempunyai pengetahuan dan ketrampilan untuk melakukan deteksi dini gangguan pendengaran di berbagai usia dengan berbagai teknik dan modalitas pemeriksaan. Sebelum melakukan kegiatan pelatihan dilakukan pre test untuk menilai pengetahuan tenaga medis yang akan mengikuti kegiatan pelatihan deteksi dini gangguan pendengaran tersebut dan akhir kegiatan dilakukan post test.

\section{Penyuluhan kesehatan pendengaran kepada karang taruna}

Kegiatan penyuluhan kesehatan pendengaran kepada anggota karang taruna Satya Kencana desa Kalibaru Kulon Kecamatan Kalibaru Kabupaten Banyuwangi Jawa Timur dilakukan dengan metode ceramah, role play interaktif dan tanya jawab. Materi yang disampaikan adalah gangguan pendengaran pada bayi baru lahir, serumen, gangguan pendengaran akibat bising, penyakit infeksi telinga dan pesbiakusis (Durning, SJ, Conran, RM., 2013; 69; Norcini, J., Friedman, MBD., 2013: 285). Sebelum dilakukan penyuluhan, dilakukan pre test terlebih dahulu untuk menilai pengetahuan peserta terhadap kesehatan pendengaran dan akhir acara dilakukan post test.

\section{HASIL DAN PEMBAHASAN}

\section{Pelatihan tenaga medis untuk meningkatkan ketrampilan deteksi dini gangguan pendengaran}

Peserta pelatihan deteksi dini gangguan pendengaran adalah tenaga medis yaitu dokter, bidan, dan perawat di Puskemas Kalibaru Kulon Banyuwangi Jawa Timur dengan jumlah peserta sebanyak 30 orang dengan rata rata hasil pre test $47,67( \pm 15,69)$. Setelah pre test, dilanjutkan dengan pemberian materi, kemudian dilanjutkan pelatihan ketrampilan deteksi dini gangguan pendengaran dan dilanjutkan dengan diskusi tanya jawab. Aktifitas pelatihan tenaga medis untuk meningkatkan ketrampilan deteksi dini gangguan pendengaran dapat dilihat pada Gambar 1.

Akhir kegiatan dilakukan post test dengan hasil rata rata 80,67 $( \pm 22,73)$. Perbandingan hasil pre test dan post test didapatkan hasil yang berbeda signifikan $(\mathrm{p}<0,0001)$ yang dapat dilihat pada Gambar 2.
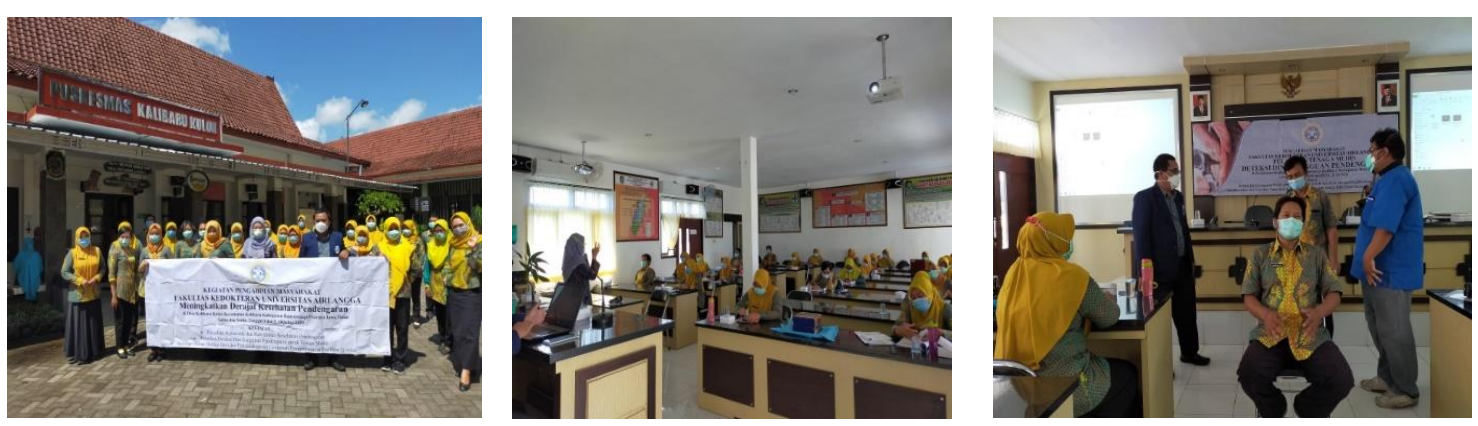
Gambar 1. Aktifitas Pelatihan Tenaga Medis untuk Meningkatkan Keterampilan Deteksi Dini Gangguan Pendengaran

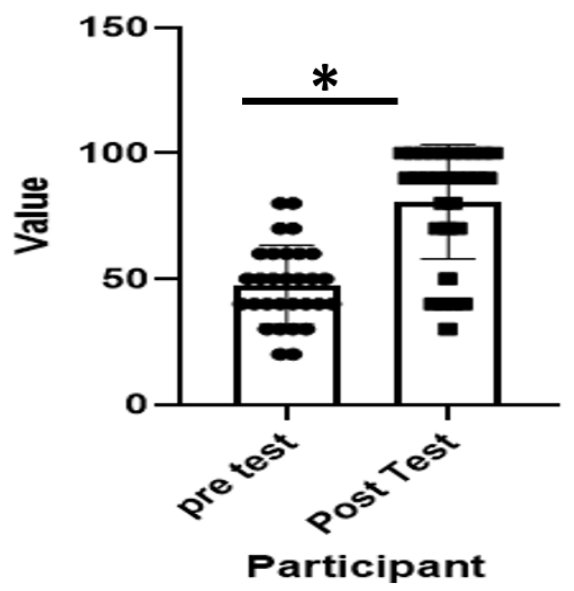

Gambar 2. Hasil Pre test dan Post test Peserta Pelatihan Deteksi Dini Gangguan Pendengaran

Pengelolaan kegiatan pelatihan pada tenaga medis tersebut, menggunakan metode kombinasi ceramah dan praktek keterampilan agar pengetahuan dan keterampilan peserta semakin meningkat untuk melakukan deteksi dini gangguan pendengaran di berbagai usia.

Kegiatan pelatihan ini sangat dibutuhkan, khususnya oleh tenaga medis di puskesmas Kalibaru Kulon. Mereka berpendapat bahwa kasus gangguan pendengaran merupakan salah satu kasus yang sering dijumpai. Pengetahuan tentang deteksi dini dan penanganan gangguan pendengaran serta keterampilan ekstraksi serumen sangat dibutuhkan dalam pelayanan kesehatan setiap hari (Browning, GG., Wormald, PJ., 2018: 919).

Rencana tindak lanjut dari kegiatan tersebut adalah melakukan pendampingan dalam bentuk sistem komunikasi dan konsultasi antara tenaga medis di area kerja puskesmas Kalibaru Kulon Banyuwangi dengan tim pengabdian masyarakat. Apabila didapatkan kasus sulit di lapangan saat melayani kesehatan masyarakat khususnya pendengaran, maka tenaga medis Puskesmas Kalibaru Kulon dapat berkomunikasi dan berkonsultasi dengan tim konsultan pengabdian masyarakat menggunakan teknologi informasi. Pendampingan ini efektif untuk penguatan pengetahuan dan ketrampilan yang didapatkan saat pelatihan (Davis, DA., Goldman, J., Perrier, L., Silver, IL., 2013: 32).

\section{Penyuluhan Kesehatan Pendengaran}

Kegiatan penyuluhan kesehatan pendengaran kepada anggota Karang Taruna Satya Kencana desa Kalibaru Kulon Kecamatan Kalibaru Kabupaten Banyuwangi Jawa Timur sebagai sasaran peserta kegiatan karena usia muda merupakan usia strategis dapat dilihat pada Gambar 3. Usia muda adalah agen perubahan di masyarakat yang apabila digerakan dengan dasar landasan pengetahuan yang baik maka akan memberikan perubahan di masyarakat (Hutchinson, L., 2003: 39). Pengetahuan yang didapatkan dari kegiatan pengabdian masyarakat tersebut akan bisa dilaksanakan dalam kehidupan sehari-hari dan dapat disampaikan kembali kepada semua kalangan baik usia yang lebih muda maupun usia yang lebih tua. Penyuluhan kesehatan pendengaran untuk karang taruna dilaksanakan dengan metode ceramah, role play, dan tanya jawab. Hasil rata-rata 
pre test $53,08( \pm 13,72)$ dan rata-rata post test $86,28( \pm 20,81)$. Perbandingan hasil pre test dan post test penyuluhan kesehatan pendengaran didapatkan hasil yang berbeda signifikan $(\mathrm{p}<0,0001)$ yang dapat dilihat pada Gambar 4.

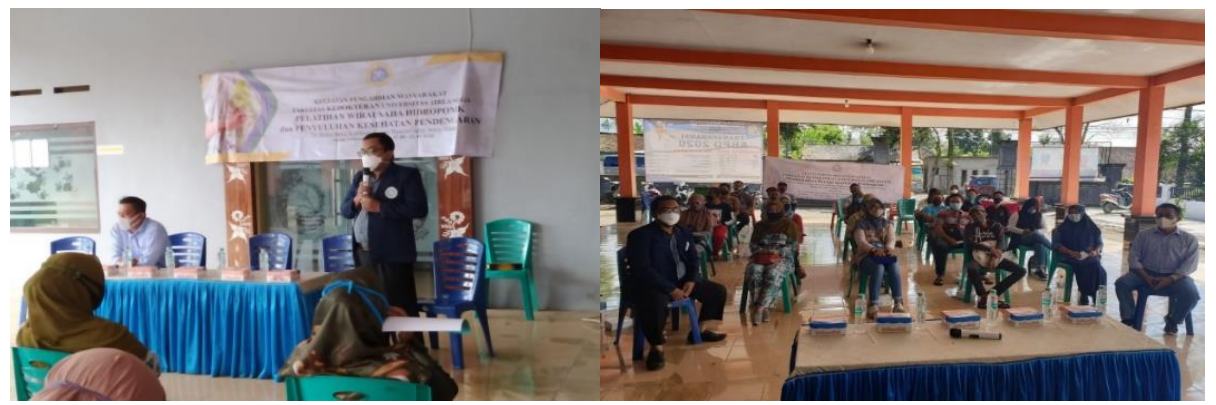

Gambar 3. Kegiatan penyuluhan kesehatan pendengaran pada karang taruna "Satya Kencana".

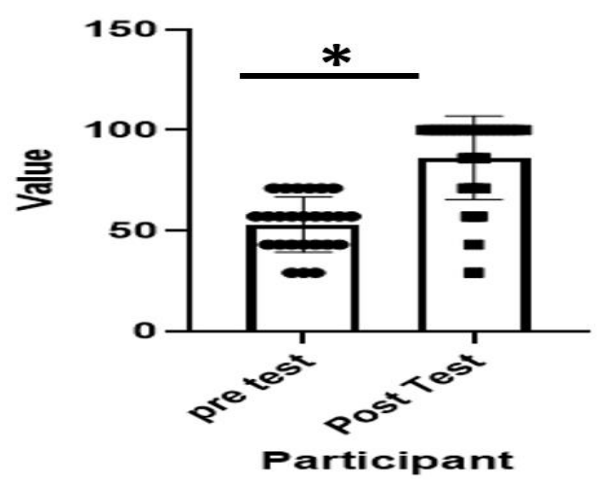

Gambar 4. Hasil Pre test dan Post test Peserta Penyuluhan Kesehatan Pendengaran

Hasil pre test dan post test kegiatan penyuluhan kesehatan pendengaran pada karang taruna memberikan perbedaan yang signifikan. Akan tetapi hasil ini adalah kondisi sesaat, sehingga sebagai kegiatan paska penyuluhan peserta dapat direkrut sebagai kader penggerak kesehatan yang akan didampingi oleh tenaga medis. Kesinambungan kemanfaatan pengetahuan akan berjalan apabila diaplikasikan dalam kehidupan seharihari dengan pendampingan tenaga medis (Hutchinson, L., 2003:39; Kementerian Kesehatan Republik Indonesia, 2016).

Selama penyuluhan peserta cukup antusias dengan kegiatan yang dilaksanakan dan berharap kegiatan bisa berkesinambungan dan berkelanjutan di masa yang akan datang. Peningkatan kapasitas pengetahuan dan ketrampilan pada kalangan kaum muda harus digencarkan, untuk memanfaatkan bonus demografi menuju Indonesia emas 2045.

\section{PENUTUP}

\section{Simpulan}

Rangkaian kegiatan pengabdian masyarakat dengan tema edukasi deteksi dini dan penatalaksanaan gangguan pendengaran dirasakan memiliki manfaat untuk para tenaga medis dan masyarakat. Kegiatan pengabdian masyarakat ini dilaksanakan dalam rangka meningkatkan peran serta masyarakat dalam pencegahan dan penanganan gangguan 
pendengaran secara dini. Tenaga medis di ujung tombak layanan kesehatan di masyarakat yaitu puskesmas diharapkan memiliki pengetahuan dan keterampilan medis untuk melakukan deteksi dini dan penatalaksanaan gangguan pendengaran sehingga mampu memberikan pelayanan kesehatan yang terbaik kepada masyarakat. Penyuluhan kesehatan pendengaran kepada karang taruna yang merupakan penduduk usia strategis diharapkan agar mereka memiliki pengetahuan tentang kesehatan pendengaran dan akan memberikan informasi tersebut kepada kelas usia yang lain.

\section{Saran}

Dalam pelaksanaan pengabdian kepada masyarakat pada akhirnya timbul pemikiran dan ketrampilan baru yaitu perlu dilakukan pelatihan yang berkesinambungan bagi tenaga medis agar memiliki kemampuan deteksi dini dan penatalaksanaan gangguan pendengaran di masyarakat serta perlu dilakukan tukar-menukar informasi, konsultasi, membangun sistem rujukan dalam penanganan gangguan pendengaran di masyarakat. Pelibatan peserta secara berkelanjutan dan berkesinambungan dalam implementasi pengetahuan di tengah-tengah masyarakat perlu dilakukan.

\section{Ucapan Terima Kasih}

Tim pengabdian kepada masyarakat mengucapkan terima kasih atas bantuan pendanaan dari dana Rencana Kegiatan Anggaran Tahunan (RKAT) Fakultas Kedokteran Universitas Airlangga Tahun Anggaran 2020 sesuai dengan Surat Keputusan Rektor Universitas Airlangga Tentang Pelaksanaan Program Pengabdian kepada Masyarakat Universitas Airlangga Tahun 2020 Nomor 532/UN3/2020 Tanggal 1 Juli 2020. Tim pengabdian kepada masyarakat juga mengucapkan terima kasih kepada pimpinan institusi terkait atas bantuan kelancaran kegiatan pengabdian kepada masyarakat yang telah dilaksanakan.

\section{DAFTAR PUSTAKA}

Browning, GG., Wormald, PJ. 2018. Clinical Examination Of The Ears And Hearing. In. Watkinson, JC., Clarke, RW. Scott Brown's Otorhinolaryngology Head and Neck Surgey. $8^{\text {th }}$ edition Volume 2. London: CRC Press Taylor \& Francis Group LLC. p. 919-971.

Davis, DA., Goldman, J., Perrier, L., Silver, IL. 2013. Continuing Professional Development. In. Dent, JA., Harden, RM. Apractical Guide for Medical Teachers. $4^{\text {th }}$ ed. London: Churcil Livingstone Elsevier.pp. 32-41.

Durning, SJ., Conran, RM. 2013. Small-Group Teaching. In. Dent, JA., Harden, RM. Apractical Guide for Medical Teachers. $4^{\text {th }}$ ed. London: Churcil Livingstone Elsevier. pp. 69-74.

Fligor, B., Chasin, M., Neitzel, R. 2009. Noise Exposure. In :Katz, J., Medwetsky, L., Burkard, R., Hood, LJ. (ed.), Handbook of Clinical Audiology. $7^{\text {th }}$ ed. Philadelphia : Lippincott Williams and Wilkins. pp. 595 - 616.

Hutchinson, L. 2003. Educational environment. In. Cantillon, P., Hutchinson, L. ABC Of Learning And Teaching In Medicine. $1^{\text {st }}$ ed. London BMJ Publishing Group Ltd. pp 39-41.

Kementerian Kesehatan Republik Indonesia. 2016. Bebaskan Keluarga dari Ketulian. Jakarta, Direktorat Pencegahan dan Pengendalian Penyakit Tidak Menular. 
Krug, E., Cieza, A., Chadha, S., Sminkey, L., Martinez, R., Stevens, G., White, K., Neumann, K., Olusanya, B., Stringer, P., Kameswaran, M., Vaughan, G., Warick, R., Bohnert, R., Henderson, L., Basanez, I., LeGeoff, M., Fougner, V., Bright, T., Brown, S. 2016. Chilhood Hearing Loss : Strategies for Prevention and Care. World Health Organization. pp 7.

Norcini, J., Friedman, MBD. 2013. Concepts In Assessment In. Dent, JA., Harden, RM. Apractical Guide for Medical Teachers. $4^{\text {th }}$ ed. London: Churcil Livingstone Elsevier. pp. 285 - 91.

Nugroho PS, Wiyadi HMS, 2009. “Anatomi Dan Fisiologi Pendengaran Perifer”. Jurnal THT-KL.Vol.2,No.2, Mei - Agustus 2009: 76 - 85

Probst, R. 2012. Anatomy and Physiology of Ear. In Probst, R., Grevers, Iro, H. Basic Otorhinolaryngology. $2^{\text {nd }}$ edition. Stuttgart: Georg Thieme Verlag. 2006. p. $153-$ 164

Puskesmas Kalibaru Kulon Banyuwangi. 2019. Laporan Tahunan Puskesmas Kalibaru Kulon Kabupaten Banyuwangi Jawa Timur Tahun 2019. Banyuwangi. Rekam Medis Puskesmas Kalibaru Kulon.

White, KR. 2009. Newborn Hearing Screening. In :Katz, J., Medwetsky, L., Burkard, R., Hood, LJ. (ed.), Handbook of Clinical Audiology. $7^{\text {th }}$ ed. Philadelphia : Lippincott Williams and Wilkins. pp. 437 - 76.

Weinstein, BE. 2009. Hearing Loss In The Elderly: A New Look At An Old Problem. In :Katz, J., Medwetsky, L., Burkard, R., Hood, LJ (ed.), Handbook of Clinical Audiology. $7^{\text {th }}$ ed. Philadelphia : Lippincott Williams and Wilkins,. pp. $631-47$. 